\title{
Importance of Ground-Glass Opacity in Long-Term Survivors of Lung Adenocarcinoma: A Leopard Cannot Change Its Spots
}

\author{
Takashi Ohtsuka, MD, PhD \\ Division of Thoracic Surgery, Department of Surgery, The Jikei University School of Medicine, Tokyo, Japan
}

In the article by Shigefuku and colleagues, ${ }^{1}$ the authors investigated factors associated with overall survival (OS) and cancer-specific survival (CSS) in lung adenocarcinoma patients who remained free from recurrence for more than 5 years after complete resection. Survival analyses showed that sex, smoking history, whole tumor size, pathological node status, pathological stage, blood vessel invasion, lymphatic permeation, visceral pleural invasion, and absence of ground-glass opacity (GGO) components were significant factors associated with OS and CSS, while multivariate analysis showed that sex, pathological node status, and absence of GGO components were significant independent factors associated with OS and CSS. In pathological stage I patients, absence of GGO components was significantly associated with poor OS and CSS. The results are interesting, and the main finding of this study is that the absence of GGO components increases the recurrence risk of lung adenocarcinoma 5 years after complete resection.

Several studies have shown that GGO components in the tumor are associated with a favorable prognosis. The GGO component on chest computed tomography (CT) is associated with the indolence of lung cancer. In the 8th edition of the TNM classification, the presence of the GGO component on chest CT is regarded as noninvasive, and is excluded while measuring the preoperative tumor

(C) Society of Surgical Oncology 2020

First Received: 26 August 2020

Accepted: 30 August 2020;

Published Online: 13 September 2020

T. Ohtsuka, MD, PhD

e-mail: ohtsuka@jikei.ac.jp diameter. ${ }^{2}$ However, after complete resection of the lung adenocarcinoma, the effect of GGO on long-term prognosis has not been determined.

For a long time, 5-year disease-free survival after complete resection remained the milestone in curing lung cancer. A few studies have investigated postoperative longterm survival in lung cancer patients who underwent complete resection. Maeda et al. reported that lung cancer recurred in $10.6 \%$ of patients at 5 years after these patients underwent resection, and local and distant metastases developed in $4.6 \%$ and $6.0 \%$ of patients, respectively. ${ }^{3}$ In the aforementioned study conducted by Shigefuku et al., the recurrence rates beyond 5 years were $1.5 \%$ and $5.8 \%$ in patients with and without GGO, respectively. The former rate was slightly better than the previously reported rate, however this may be due to the high percentage of patients with GGO included in this study.

Some drawbacks exist in the study. For instance, the ratio of GGO has not been considered. In a recent study conducted by the Japan Clinical Oncology Group Lung Cancer Surgical Study Group, consolidation/tumor ratio $\leq 0.5$, which is identical to $50 \%$ of GGOs in the tumor, showed excellent prognosis. ${ }^{4}$ The GGO ratio could be important for the present study. Additionally, the type of resection (lobectomy, segmentectomy, or pneumonectomy) was not described, which could have affected the prognosis. Primary lung cancers with GGO have increased recently ${ }^{5}$ and are gaining increasing attention. Moreover, the data of multiple nodules were not described in this study. Distinguishing the recurrence of primary lung cancer from metachronous tumors was difficult without pathologic specimens, and this issue could be subsequently addressed.

Thus, the absence of GGO is a predictor of poor longterm prognosis. Furthermore, a period of 5 years is not sufficient to ascertain whether lung cancer is cured. GGO 
indicates dormancy of lung cancer, and it is interesting that the dormancy of GGO lasts for a long time after complete resection of the adenocarcinoma.

The prognostic impact of GGO can be expected to become an important clinical issue, and could therefore be the subject of future studies. Based on the present research, large-scale prospective studies of lung adenocarcinoma should be performed with the aim of understanding the impact of GGO on long-term prognosis.

DISCLOSURES Takashi Ohtsuka declares no conflicts of interest.

\section{REFERENCES}

1. Shigefuku S, Shimada Y, Hagiwara M, et al. Prognostic significance of ground-glass opacity components in 5-year survivors with resected lung adenocarcinoma. Ann Surg Oncol. 2020. http s://doi.org/10.1245/s10434-020-09125-x.
2. Travis WD, Asamura H, Bankier AA, et al. The IASLC Lung Cancer Staging Project: Proposals for Coding T Categories for Subsolid Nodules and Assessment of Tumor Size in Part-Solid Tumors in the Forthcoming Eighth Edition of the TNM Classification of Lung Cancer. J Thorac Oncol. 2016;11(8):1204-1223.

3. Maeda R, Yoshida J, Hishida T, et al. Late recurrence of non-small cell lung cancer more than 5 years after complete resection: incidence and clinical implications in patient follow-up. Chest. 2010;138(1):145-150.

4. Ito H, Suzuki K, Mizutani T, et al. Long-term survival outcome after lobectomy in patients with clinical T1 N0 lung cancer. J Thorac Cardiovasc Surg. Epub 11 Jan 2020. https://doi.org/10. 1016/j.jtcvs.2019.12.072.

5. Kim HK, Choi YS, Kim J, Shim YM, Lee KS, Kim K. Management of multiple pure ground-glass opacity lesions in patients with bronchioloalveolar carcinoma. J Thorac Oncol. 2010;5(2):206-210.

Publisher's Note Springer Nature remains neutral with regard to jurisdictional claims in published maps and institutional affiliations. 